\title{
Quality of Emulsions Containing Fat Blends Modified by Enzymatic Catalysis
}

\author{
Małgorzata Kowalska ${ }^{1, *(D)}$, Magdalena Woźniak ${ }^{1}$, Anna Zbikowska ${ }^{2}$ D , Eva Ivanišová ${ }^{3}$ and $^{\text {Artur Molik }}{ }^{1}$ (D) \\ 1 Faculty of Chemical Engineering and Commodity Science, Kazimierz Pulaski University of Technologies and \\ Humanities, Chrobrego 27, 26-600 Radom, Poland; m.wozniak@uthrad.pl (M.W.); \\ artur.molik@uthrad.pl (A.M.) \\ 2 Department of Food Technology and Assessment, Institute of Food Sciences, Warsaw University of Life \\ Sciences-SGGW (WULS-SGGW), 02-772 Warsaw, Poland; anna_zbikowska@sggw.pl \\ 3 Department of Technology and Quality of Plant Products, Faculty of Biotechnology and Food Sciences, \\ Slovak University of Agriculture, Tr. A. Hlinku 2, 94976 Nitra, Slovakia; eva.ivanisova@uniag.sk \\ * Correspondence: mkowalska7@vp.pl; Tel.: +48-48-3617547
}

check for updates

Citation: Kowalska, M.; Woźniak, M.; Zbikowska, A.; Ivanišová, E.; Molik, A. Quality of Emulsions Containing Fat Blends Modified by Enzymatic Catalysis. Catalysts 2021 11, 453. https://doi.org/10.3390/ catal11040453

Academic Editors: Paulina Majewska, Magdalena Klimek-Ochab and Małgorzata Brzezińska-Rodak

Received: 13 March 2021

Accepted: 29 March 2021

Published: 31 March 2021

Publisher's Note: MDPI stays neutral with regard to jurisdictional claims in published maps and institutional affiliations.

Copyright: (c) 2021 by the authors. Licensee MDPI, Basel, Switzerland. This article is an open access article distributed under the terms and conditions of the Creative Commons Attribution (CC BY) license (https:/ / creativecommons.org/licenses/by/ $4.0 /)$.

\begin{abstract}
The purpose of this study was to evaluate the effect of the enzymatic modification of muton tallow and hemp seed oil fat blends. An attempt of application of these fat blends as fat phases in emulsion systems with various amount of carboxymethylcellulose was made. Fat blends before and after enzymatic catalysis were assessed in the context of polar and non-polar fractions content, antioxidant activity, oxidative stability and texture. Emulsions were investigated in the terms of their stability, color, microstructure, droplets diameter, and viscosity. The study revealed that emulsions containing as a fat phases modified blends with greater share of mutton tallow showed more favorable properties, and greater stability. The presented emulsions are a model dispersion system, after adjustment of the additives they could be used as chemical, food or cosmetic products.
\end{abstract}

Keywords: enzymatic biocatalysis; fats; diacylglycerol; lipozyme; emulsions

\section{Introduction}

One of the possibilities for altering the functionality of fats in order to increase their application without substantial change of the contents of minor compounds is enzymatic modification. Lipases can be employed in the modification of the chemical structure of natural triacylglycerols (TAGs) to improve their physicochemical properties as well as their health benefits. The concept of structured TAGs implies modification of the fatty acids composition, their location on the glycerol backbone, and improvement of the physicochemical properties of lipids. Studies have shown that enzymatically modified TAGs exhibit similar or, in some cases, greater benefits compared to blended oils with similar fatty acid composition [1]. Such an example may be the production of a new fat enriched with unsaturated fatty acids as a result of enzymatic catalysis. Choosing the proper composition of the reactants, i.e. oil rich in unsaturated fatty acids, and interesterification with mutton or beef tallow in the presence of selective lipase allows to obtain fat product with more favorable nutritional characteristics, and often with a better structure and more desirable consistency [2,3]. Enzymes as biocatalysts has several advantages over chemical catalysts. The most remarkable is their selectivity, which cannot be achieved by chemical catalysis. Besides, the technological process contributes to the formation of a product with a low content of byproducts [4]. The selectivity of the lipases leads to the introduction of the desired fatty acids into precisely defined positions of the TAGs. Thus, it allows to obtain fat products with a structure unparalleled in nature. Additionally, the use of biocatalysts in interesterification allows the reaction to proceed with a sufficient speed, under mild conditions, which contributes to easier control of the process [5]. Enzymatic catalysis also gives a chance to obtain modified fat free of trans isomers, which from the nutritional point of view gives the product an unquestionable advantage [6]. 
Water present in the initial reaction system plays a significant role in the enzymatic interesterification process. Its presence is related to the reactivity of the catalyst [7]. Increased amount of water in the system shifts the reaction equilibrium in favor of the hydrolysis reaction. Products of this process can be, in addition to TAGs, also mono-, diacylglycerols and free fatty acids [3]. Proper control of this process allows to obtain a new fat product that can be used as a fat base for emulsion [3]. Diacylglycerols (DAGs) can also be obtained by enzymatic methods with the use of lipolytic enzymes, direct synthesis of fatty acids and glycerol, alcoholysis or hydrolysis of fats. Diacylglycerols have valuable health-promoting properties, but are also known as emulsifiers and stabilizers in various food products, cosmetics and pharmaceuticals [8].

Developing an emulsion product that has high stability while meeting consumer demands is relatively difficult [9]. McClements [10] mentioned that emulsion quality parameters are the result of complex interactions. Some of the most important characteristics of emulsion systems are stability, rheological properties, and appearance [11]. Hence, stabilizers are added to these systems, among which are emulsifiers and texture modifiers [11]. In the produced systems, the aforementioned DAGs were used as emulsifiers, while carboxymethylcellulose $(\mathrm{CMC})$ was used as texture modifier. $\mathrm{CMC}$, is a derivative of cellulose and meets the needs of many industries including food and pharmaceuticals [12]. CMC as a component of emulsion formulations stabilizes it, increases its viscosity, and improves its texture properties [13].The purpose of this study was to evaluate the effect of the enzymatic modification of muton tallow and hemp seed oil fat blends and the attempt of application of these fats as a fat phases in emulsions with various amount of carboxymethylcellulose. Mutton tallow is considered a waste product of the meat industry and contains in its composition mainly saturated fatty acids. To enrich it with polyunsaturated fatty acids, fatty blends of mutton tallow and hemp seed oil, which is a source of omega- 3 and omega- 6 acids, were prepared [14].

\section{Results and Discussion}

\subsection{Fats}

The conditions of the enzymatic modification reaction were selected to obtain the planned amount of the polar fraction (monoacylglycerols and diacylglycerols MAG and DAG) [2]. The enzymatic modification reaction, in this case the interesterification, was carried out in the presence of lipase from Rhizomucor miehei as a catalyst. The reaction equilibrium was shifted towards the formation of intermediates such as mono- and diacylglycerols by increasing the water concentration in reaction environment [15]. In the study an attempt was made to obtain a fat blend already enriched with a sufficient amount of effective emulsifiers that could be used as the fat base of the emulsions with carboxymethylcellulose.

Analyzing the obtained results, a clear increase in the polar fraction content was observed, including an increase in free fatty acids and diacylglycerols content as compared to fats before interesterification (Figure 1). The level of the amount of diacylglycerols after the enzymatic modification of fat blends in the polar fraction was in the range between $56.5 \%$ for the modified blend (mutton tallow:hemp seed oil) M MT:HSO 50:50 to $61.1 \%$ for the blend M MT:HSO 25:75, while for the corresponding blends before the enzymatic catalysis it was 0 (Figure 1). It was also observed that the content of monoacylglycerols in the blends obtained as a result of enzymatic catalysis was slightly increased. In general, it remained close for all blends subjected to modification and accounted for 0.6 to $4.2 \%$ of the polar fraction. The highest level of this component was noted for the modified blend prepared from the same amount of animal and vegetable fat. Certain amounts of monoacylglycerols were also recorded for the initial blends (not subjected to catalysis), whose share in the polar fraction was from 0 to $17.4 \%$ (Figure 1). According to Macare [16], the level of monoacylglycerols in the interesterification reactions should be low. This is due to the high reactivity of these compounds, namely the ability to convert into diacylglycerols as a result of esterification with fatty acids present in the reaction medium. The data obtained from the results of the amount of diacylglycerols confirmed the above literature 
reports, they also indicate that the share of diacylglycerols in the polar fraction of modified fat blends remained at the level of nearly $60 \%$ in relation to the other ingredients, i.e. free fatty acids and monoacylglycerols.

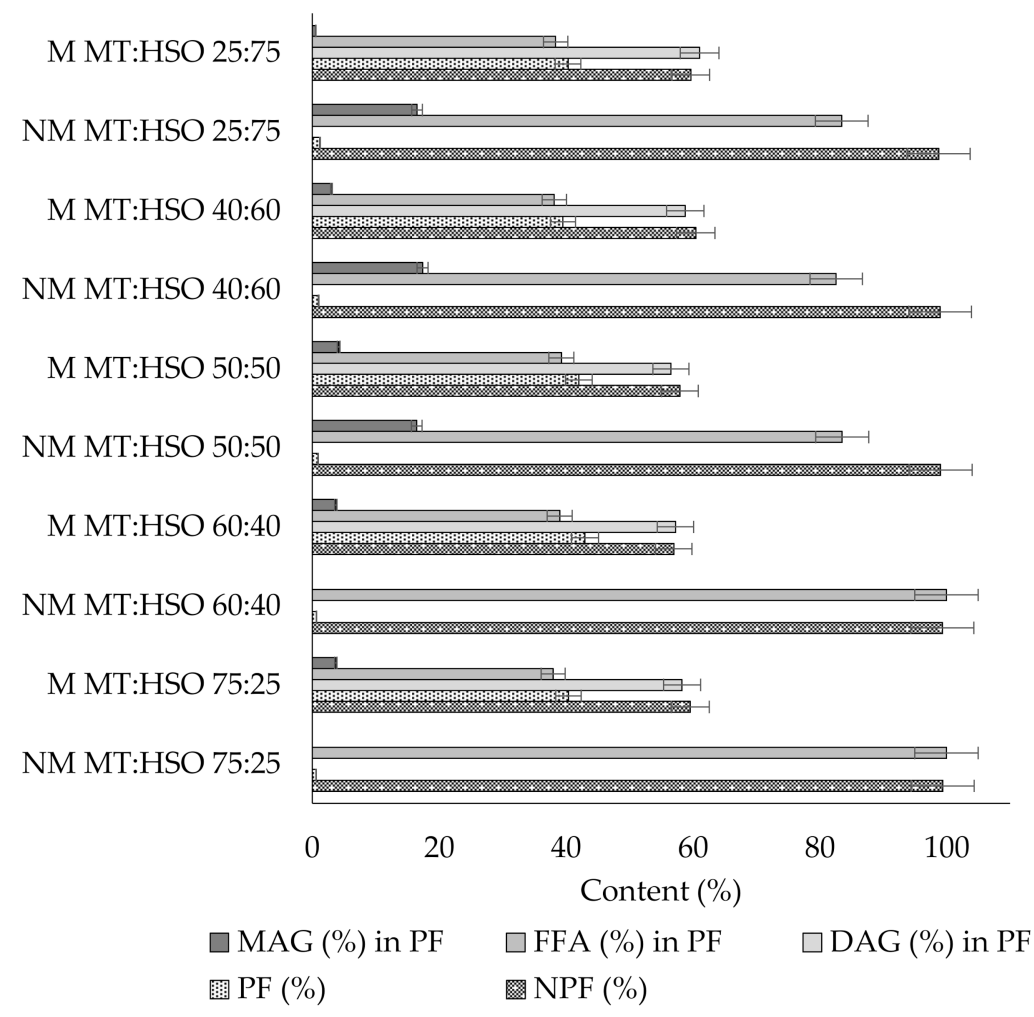

Figure 1. Polar and non-polar fractions content of fat blends subjected and not subjected to enzymatic catalysis (PF-polar fraction; NPF-non-polar fraction; DAG—diacylglycerols; MAGmonoacylglycerols; FFA—free fatty acids; NM—non-modified; M—modified; MT—mutton tallow; HSO—hemp seed oil).

Analyzing the results of the acid value and related free fatty acids content, it was confirmed that enzymatic catalysis of fat blends increased the content of free fatty acids in relation to the initial blends (Figure 1). The lowest content of free fatty acids was found in the polar fraction of the M MT: HSO 40:60 (38.2\%) blend, while the highest for M MT: HSO $60: 40(39.0 \%)$ blend. The results of the non-polar fraction (or the amount of triacylglycerols) indicated that both the hydrolysis and re-esterification processes of TAGs took place in the fat blends. The amount of TAGs in the modified products remained at the level of $57-60.5 \%$, while for the same unmodified blends the amount of TAGs was in the range of 98.8-99.4\% (Figure 1).

Fats are exposed to oxidation, which have an impact on the deterioration of their organoleptic properties, thus reducing their nutritional value and resulting in the formation of toxic oxidation products. This is especially the case for fats containing polyunsaturated fatty acids and fats that are inappropriately stored with exposure to heat and light. One of the parameters monitoring the quality of fats is the determination of the antioxidant activity [17].

Analyzing the antioxidant activity of fats, it was observed that hemp seed oil revealed the highest value of this parameter $(64.8 \mathrm{mM} \mathrm{TEAC} / \mathrm{kg})$. According to the authors Leonard et al. [18] hemp seed oil is rich for antioxidants, as well as natural pigments and chlorophylls. Mutton tallow was characterized by lower antioxidant activity $(36.8 \mathrm{mM}$ TEAC $/ \mathrm{kg}$ ) than hemp seed oil, although it was observed that when mixed with hemp seed oil, the activity increased accordingly. 
Analyzing the blends before modification, it was observed that the highest antioxidant activity was recorded for the blend containing $25 \% w / w$ of hemp seed oil (Figure 2). For the blends for which the enzymatic catalysis was carried out, the blend M MT:HSO 40:60 (38.5 TEAC mM) was characterized by the highest antioxidant activity. Moreover, it was observed that the smallest changes in the antioxidant activity after the enzymatic catalysis were recorded for the MT:HSO 50:50 and MT:HSO 40:60 fat blends. In general, the enzymatic modification of fats reduced the antioxidant activity. The above information is consistent with the information provided by the authors [19] who informed that the interesterification of fats reduced their quality.

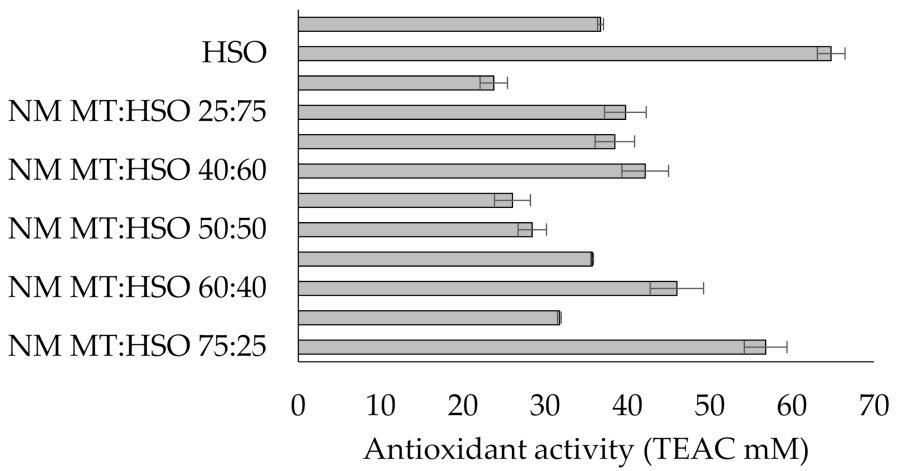

Figure 2. Antioxidant activity of fats (Legend: NM-non-modified; M-modified; MT—mutton tallow; HSO-hemp seed oil; TEAC—Trolox equivalent antioxidant capacity)

Rancimat test is an accelerated oxidation analysis which measures the time required by edible fats to form by-products of thermally-induced peroxidation [20]. Induction time determined by Rancimat is important parameter which testifies about oxidative stability of fat. It was found that the induction times of all fats ranged from $0.82 \mathrm{~h}$ to $3.03 \mathrm{~h}$ (Figure 3). The highest induction time was recorded for raw mutton tallow $(3.03 \mathrm{~h})$. The second raw fat used - hemp seed oil, was characterized by a much lower value of this parameter $(1.38 \mathrm{~h})$. Whereas when the oil was mixed with mutton tallow, the induction time values were higher in proportion to the amount of animal fat. More favorable values of this parameter were noted for fat blends before the modification process. The modified fats showed reduction of nearly half in the induction times compared to the unmodified samples (Figure 3). According to Ledóchowska and Datta [21], the reduction of oxidative stability may be dictated by the incorporation of polyenoic fatty acids derived from hemp seed oil into the external positions of triacylglycerol, which creates more favorable oxygen access to these acids and thus their oxidation.

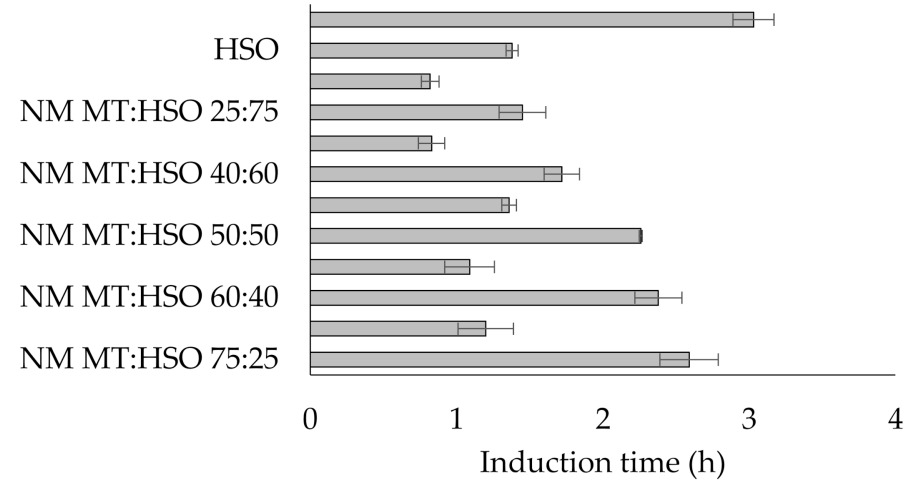

Figure 3. Induction time of fats. (Legend: NM-non-modified; M-modified; MT—mutton tallow; HSO—hemp seed oil). 
The texture of fats is also an important feature in assessing their quality and application. The hardness or spreadability of fats is determined by their composition, especially the type of fat used for production, i.e. the proportion of animal fat to vegetable oil. Increasing the content of solid fats increases the hardness, but in the same time reduces the spreadability of the product. The addition of vegetable oil to animal fat significantly improves the spreadability, thus reducing the hardness of the final product. It is related to the increased share of the fat fraction with a low melting point. From the analysis of the hardness values obtained for the examined fat blends, it was observed that the highest hardness was noted for in fats with a higher addition of mutton tallow. Decreasing its share in the blend before modification resulted in a decrease in the values of this parameter, and the lowest value was recorded as $10.5 \mathrm{~g}$ (non-modifiedMT:HSO 25:75) (Table 1). Similarly, for catalyzed fats, a higher proportion of hemp seed oil resulted in a reduction in hardness. Hardness of fats subjected to enzymatic modification was much lower than for unmodified blends. Hydrolysis of ester bonds, then resynthesis of TAGs, exchange of fatty acid positions affect the rheological properties of fats such as consistency, viscosity and hardness [22]. Similar observations were noted for adhesion force, i.e. the modification process caused an increase in the value of this parameter compared to the corresponding unmodified blends. However, the greatest changes were recorded for fats with the highest share of mutton tallow. On the other hand, for the fat blend containing the highest share of hemp seed oil, the changes in this parameter were insignificant (Table 1).

Table 1. Hardness and adhesive force of the fat blends.

\begin{tabular}{cccccc}
\hline Fat Blend & Hardness (g) & $\begin{array}{c}\text { Adhesive } \\
\text { Force (g) }\end{array}$ & Fat Blend & Hardness (g) & $\begin{array}{c}\text { Adhesive } \\
\text { Force (g) }\end{array}$ \\
\hline $\begin{array}{c}\text { NM MT:HSO } \\
\text { 75:25 }\end{array}$ & 885.5 & -128.5 & $\begin{array}{c}\text { M MT:HSO } \\
75: 25\end{array}$ & 446.0 & -43.0 \\
$\begin{array}{c}\text { NM MT:HSO } \\
\text { 60:40 }\end{array}$ & 740.5 & -116.0 & $\begin{array}{c}\text { M MT:HSO } \\
60: 40\end{array}$ & 104.5 & -12.0 \\
$\begin{array}{l}\text { NM MT:HSO } \\
\text { 50:50 }\end{array}$ & 310.5 & -37.0 & $\begin{array}{c}\text { M MT:HSO } \\
50: 50\end{array}$ & 24.0 & -4.0 \\
$\begin{array}{l}\text { NM MT:HSO } \\
\text { 40:60 }\end{array}$ & 109.0 & -15.0 & $\begin{array}{c}\text { M MT:HSO } \\
40: 60\end{array}$ & 12.0 & -3.0 \\
$\begin{array}{l}\text { NM MT:HSO } \\
\text { 25:75 }\end{array}$ & 10.5 & -3.5 & $\begin{array}{c}\text { M MT:HSO } \\
25: 75\end{array}$ & 2.5 & -2.5 \\
\hline
\end{tabular}

(Legend: NM—non-modified; M—-modified; MT—-mutton tallow; HSO—hemp seed oil).

\subsection{Emulsions}

On the basis of the new fat blends obtained as a result of enzymatic catalysis, dispersion systems were prepared, the details of which are presented in Table 2. The stability of the emulsion depends on numerous interactions occurring in this system. The type of and amount of emulsifier as well as viscosity modifier are not without significance in stabilizing such a system. The type of fat used is an important factor as well. In the presented work, we proposed a modified fat blends as the oil phases, which was also equipped with a certain amount of emulsifiers (diacylglycerols). The amount of viscosity modifier used was the factor that differentiates all the emulsions. One of the specified parameters that actually allow to determine the stability of dispersion systems is the Turbiscan stability index (TSI). 
Table 2. Emulsions composition.

\begin{tabular}{|c|c|c|c|c|c|c|c|c|c|c|c|c|c|c|c|c|}
\hline Phase & Component & E1 & E2 & E3 & E4 & E5 & E6 & E7 & E8 & E9 & E10 & E11 & E12 & E13 & E14 & E15 \\
\hline \multirow{2}{*}{$\begin{array}{c}\text { Oil } \\
\text { phase }\end{array}$} & $\begin{array}{l}\text { MT:HSO ratio } \\
\quad(w / w)\end{array}$ & & $75: 25$ & & & 60:40 & & & $50: 50$ & & & $40: 60$ & & & $25: 75$ & \\
\hline & $\begin{array}{l}\text { Modified fat } \\
\text { blend } \\
(\% w / w)\end{array}$ & & & & & & & & 30.0 & & & & & & & \\
\hline \multirow{2}{*}{$\begin{array}{l}\text { Aqueous } \\
\text { phase }\end{array}$} & $\begin{array}{c}\text { CMC } \\
(\% w / w)\end{array}$ & 0.6 & 0.8 & 1.0 & 0.6 & 0.8 & 1.0 & 0.6 & 0.8 & 1.0 & 0.6 & 0.8 & 1.0 & 0.6 & 0.8 & 1.0 \\
\hline & $\begin{array}{l}\text { Water } \\
(\% w / w)\end{array}$ & \multicolumn{15}{|c|}{ Up to 100.0} \\
\hline- & $\begin{array}{l}\text { Preservative } \\
\quad(\% w / w)\end{array}$ & \multicolumn{15}{|c|}{1.0} \\
\hline
\end{tabular}

(Legend: MT—mutton tallow; HSO—hemp seed oil; CMC—carboxymethylcellulose).

TSI is a parameter, which can be used for determination of the changes in emulsions and is obtained as the sum of all destabilization phenomena taking place during the monitoring process. High TSI values indicate decreased stability of the system [23]. The most favorable values indicating a low level of instability were recorded for two emulsions E4 and E5 (Figure 4). For these systems, the TSI values did not exceed 2.8 after 30 days of emulsions preparation. Signals of instability of were indicated by high values of TSI for emulsions E9-E15. The lowest value for the mentioned systems was recorded as 12.6 for emulsion E9, and the highest for emulsion 51.2 for E13. A clear deterioration of the stability was noted for the emulsions containing the modified fat with the highest share of hemp seed oil. Especially for two emulsions, E13 and E15, already on the fourth day of storage the TSI values reached the values of 19.4 and 29.8, respectively. It can clearly be concluded that the type of fat had an influence on the quality of the emulsions while the amount of viscosity modifier introduced into the system did not affect this parameter.

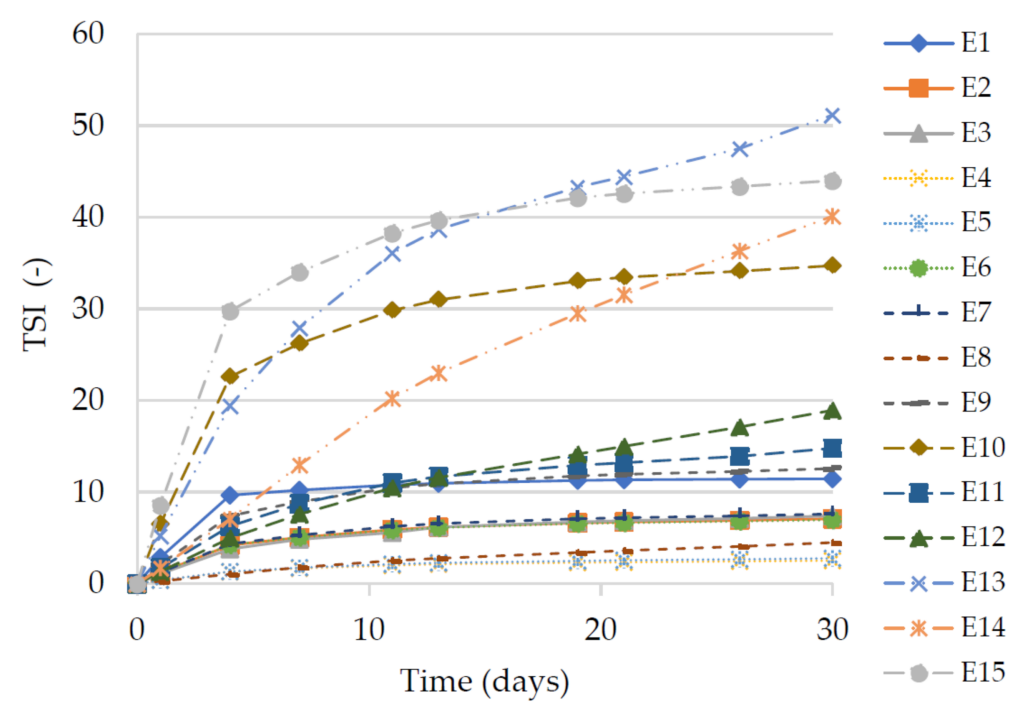

Figure 4. Values of TSI for emulsions E1-E15. Legend for E1-E15 is provided in Table 2.

To confirm the above data, the results of changes in the intensity of back scattered light determined as mean $\triangle \mathrm{BS}(\%)$ in the middle zone of the measuring cell $(14-28 \mathrm{~mm})$ recorded by Turbiscan Lab were presented on Figure 5. The emulsions E13, E14, and E15 showed the greatest increase in the size of dispersed phase droplets. The significant change of mean $\triangle \mathrm{BS}(\%)$ in middle zone of the measuring cell indicates ongoing processes of droplet aggregation and coalescence of these emulsions. These phenomena were not observed for emulsions E4, E5, but it was noticed to a very small extent for emulsions E6, E7, E8. 


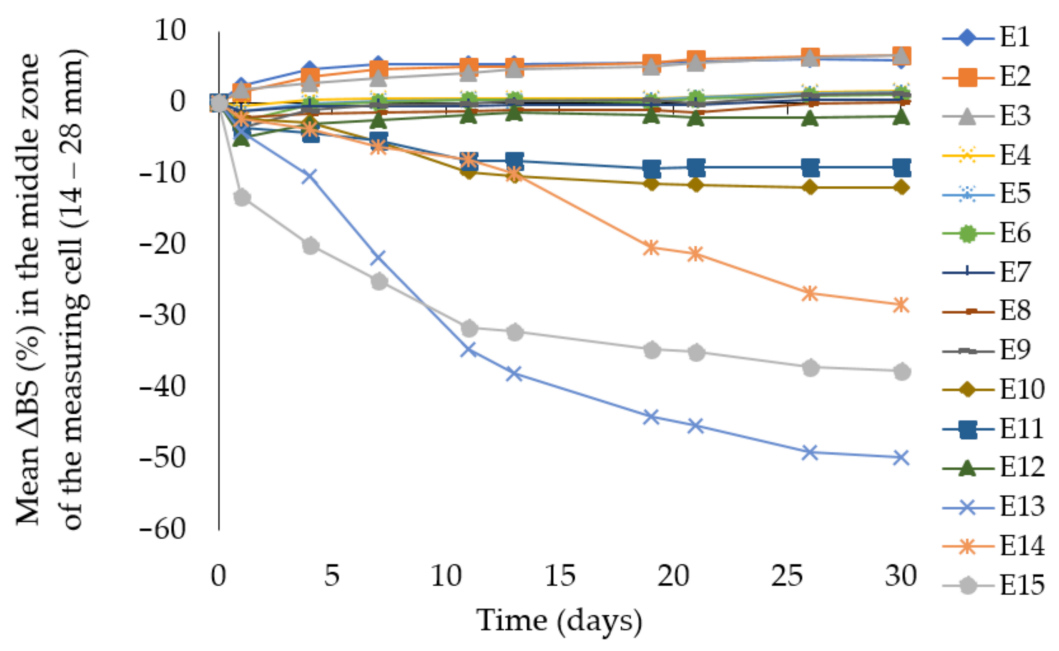

Figure 5. Mean $\triangle \mathrm{BS}(\%)$ in the middle zone of the measuring cell (14-28 mm) for emulsions E1-E15. Legend for E1-E15 is provided in Table 2.

The creaming process that took place in the systems is shown in Figure 6 as a peak thickness in the bottom zone of the measuring cell (0-14 $\mathrm{mm})$ and presents clarification kinetics during the storage of the emulsion (30 days). The obtained data revealed that the most dynamic process of clarification in the lower part of the vial was for emulsions E13 and E15, which has started after the first few days of storage. The sixth day from preparation of both emulsions can be considered as the day of these emulsions breakdown.

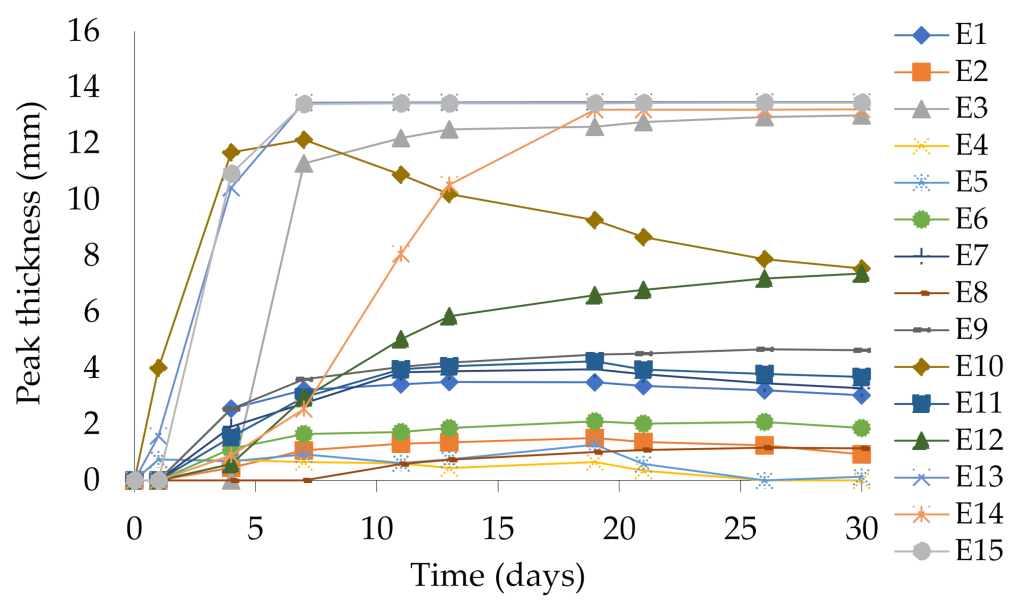

Figure 6. Peak thickness in the bottom zone of the measuring cell (0-14 mm) for emulsions E1-E15. Legend for E1-E15 is provided in Table 2.

The droplet size affects the stability of dispersion systems, hence the analysis of the distribution or the mean size of these particles plays an important role in the research and quality control of these systems. Different measuring techniques are used depending on the particle size range. However, with any method of measurement, the analyzed sample must be appropriately sampled to provide results that are representative of the entire population. In this study, we used the particle size measurement method using an optical microscope. We used the same tool to assess the microstructure of the emulsions. From the analysis of the mean droplet size of the emulsions performed $24 \mathrm{~h}$ after their preparation, it was observed that the emulsions E4, E5, E6 were characterized by the smallest diameters, 3.9, 4.0 and $4.8 \mu \mathrm{m}$ respectively. The smallest droplet diameter increase after storage (30 days) were also observed in these emulsions (Table 3). The structure of these emulsions after $24 \mathrm{~h}$ was homogeneous, without the presence of particle agglomerates. Also, no single larger droplets in the system were observed (Figure 7). The droplet diameter distribution of these 
emulsions was one of the narrowest and ranged from 0.7 to $16.7 \mu \mathrm{m}$. The greatest mean diameters and the widest particle distributions were recorded for the E7-E15 emulsions, although the least favorable distribution and the greatest mean diameter were noted for E15. For this emulsion, the highest increase in average droplet diameter was also noted after 30 days of storage $(3.8 \mu \mathrm{m})$. For E15 as well as for emulsions containing the same fat blend but different thickener content (E13 and E14), the microstructure was far from the regularly arranged particles of the dispersed phase characterizing the proper emulsion system. There were visible voids and clusters of single droplets informing about the aggregation phenomenon (Figure 7). It should be noted that in all systems containing the same fat blend but different viscosity modifier content, an increase in droplet diameter was observed with an increase in the viscosity modifier content (Table 3).

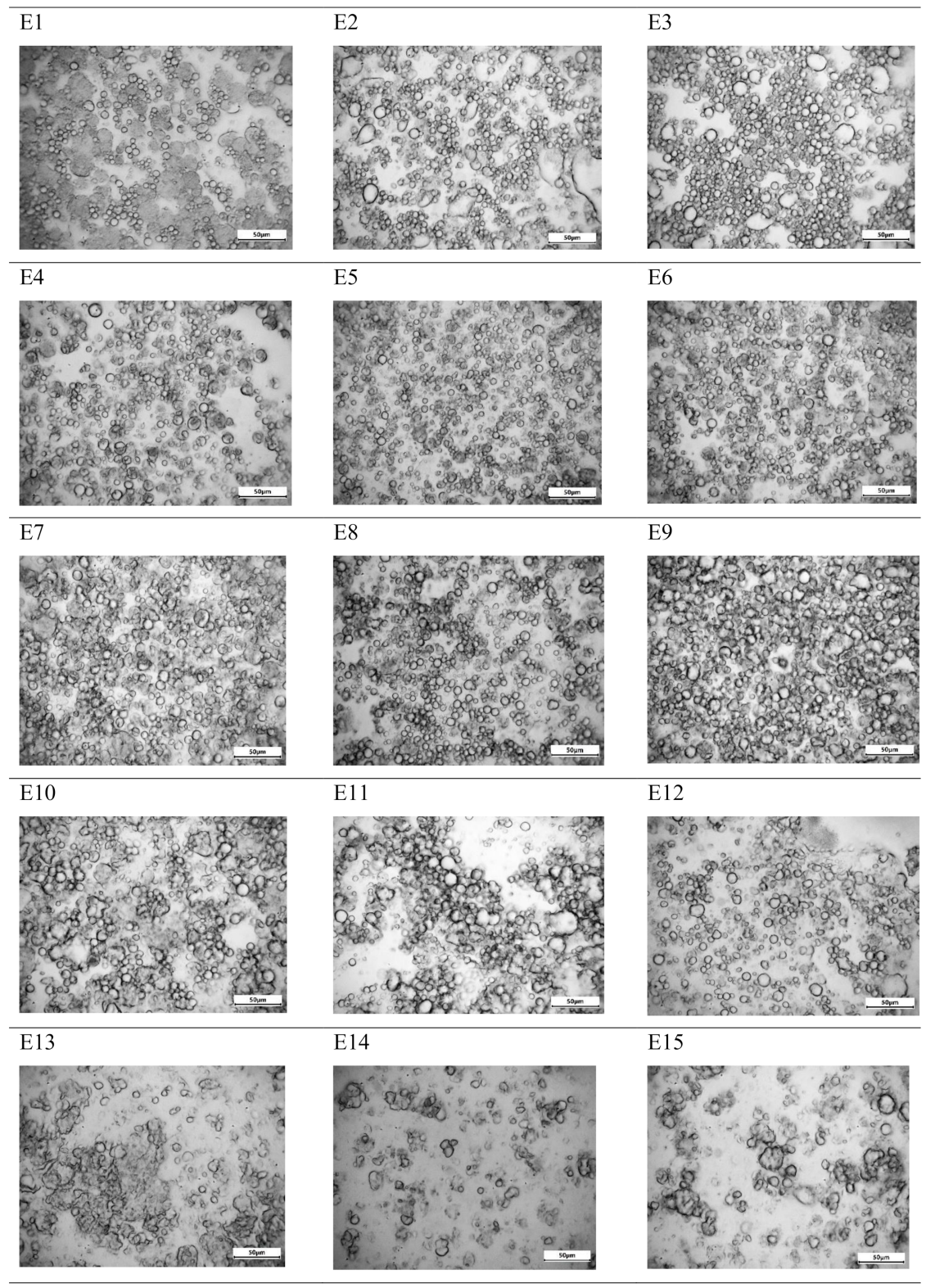

Figure 7. Optical microphotographs of E1-E15 emulsions determined $24 \mathrm{~h}$ after their preparation. Legend for E1-E15 is provided in Table 2. 
Table 3. Droplet diameter for freshly prepared ( $24 \mathrm{~h}$ from preparation) and stored $\left(2-7^{\circ} \mathrm{C}, 30\right.$ days) of emulsions E1-E15. Legend for E1-E15 is provided in Table 2.

\begin{tabular}{ccccccc}
\hline \multirow{2}{*}{ Emulsion } & \multicolumn{2}{c}{$\begin{array}{c}\text { Measurement for Emulsions after } \mathbf{2 4} \mathbf{h} \\
\text { of Their Preparation }\end{array}$} & \multicolumn{3}{c}{$\begin{array}{c}\text { Measurement for Emulsions after } \\
\text { 30 Days of Storage }\end{array}$} \\
\cline { 2 - 7 } & $\begin{array}{c}\text { Minimum } \\
(\boldsymbol{\mu m})\end{array}$ & $\begin{array}{c}\text { Maximum } \\
(\boldsymbol{\mu m})\end{array}$ & $\begin{array}{c}\text { Mean } \\
(\boldsymbol{\mu m})\end{array}$ & $\begin{array}{c}\text { Minimum } \\
(\boldsymbol{\mu m})\end{array}$ & $\begin{array}{c}\text { Maximum } \\
(\boldsymbol{\mu m})\end{array}$ & $\begin{array}{c}\text { Mean } \\
(\boldsymbol{\mu m})\end{array}$ \\
\hline E1 & 1.0 & 23.2 & 5.3 & 1.8 & 25.4 & 6.4 \\
E2 & 1.4 & 21.3 & 5.5 & 1.0 & 25.5 & 5.6 \\
E3 & 0.7 & 22.6 & 5.7 & 0.9 & 30.4 & 5.9 \\
E4 & 0.9 & 15.6 & 3.9 & 0.8 & 14.9 & 4.2 \\
E5 & 0.7 & 12.3 & 4.0 & 0.7 & 16.7 & 4.1 \\
E6 & 0.8 & 16.7 & 4.8 & 1.4 & 24.5 & 4.9 \\
E7 & 1.4 & 22.5 & 6.5 & 1.4 & 25.5 & 6.9 \\
E8 & 1.6 & 17.1 & 5.7 & 1.7 & 20.8 & 6.3 \\
E9 & 1.8 & 31.2 & 7.1 & 2.2 & 32.2 & 7.6 \\
E10 & 2.0 & 27.4 & 7.2 & 1.7 & 31.1 & 9.1 \\
E11 & 2.1 & 21.2 & 7.7 & 2.9 & 46.0 & 10.2 \\
E12 & 1.5 & 16.6 & 6.5 & 2.4 & 49.0 & 8.2 \\
E13 & 2.0 & 30.5 & 7.0 & 3.0 & 40.5 & 10.5 \\
E14 & 1.7 & 18.8 & 7.2 & 2.0 & 21.5 & 7.6 \\
E15 & 2.5 & 27.0 & 8.5 & 3.2 & 57.3 & 12.3 \\
\hline
\end{tabular}

Visible light is scattered only by the emulsion droplets. Due to its small sizes, visible light is partially scattered and partially transmitted by the emulsion particles, so it can be concluded that the color of the emulsion depends on the interaction of the system droplets with light waves and the related reflection, adsorption, transmission and scattering phenomena [24]. The change in the color of the emulsion can therefore be a factor controlling the phenomena taking place in the emulsion (destabilization changes). Yellowing of the initially white formulations is usually caused by oxidation or thermal decomposition of the emulsion components, while lightening of the emulsion can indicate agglomeration of the dispersed phase particles. It was found that the values of the brightness parameter $\left(\mathrm{L}^{*}\right)$ measured after 30 days of storage of the emulsions were lower than the values measured $24 \mathrm{~h}$ after the emulsions were prepared. This meant that all the emulsions darkened slightly. The smallest changes in this parameter were recorded for emulsion E1, while for the remaining ones the changes were $+/-3$ to 5 (Figure 8). The lightest emulsions were those containing a higher addition of mutton tallow in the fat blend used as the fat base of the emulsion. However, when it comes to the $\mathrm{a}^{*}$ parameter, slight changes were noted for stored emulsions or no changes in the value of this parameter were recorded. The values were slightly changing towards the green color. It was also noted that after 30 days of storage, the $b^{*}$ parameter values increased for the E1-E12 emulsions, while for the three emulsions with the highest share of hemp seed oil in fat blend (E13-E15), a decrease in the values of this parameter were observed.

Color determination of emulsion systems can be an auxiliary tool in detecting the phenomenon of coalescence. As McClements [11] points out, emulsion systems in which this type of instability occurs may be characterized by more intense color. According to Patras et al. [24], perceivable color differences can be classified by total color difference (TCD). TCD values greater than 3 are interpreted as very pronounced, between 1.5 and 3 as pronounced, and below 1.5 as low. Referring to this classification, in the case of the prepared emulsions most of them remained as the ones whose changes were recorded in the range from 0 to 3. Emulsions E3, E8, E11, E12, E13, E14 were characterized by values above 3 , which meant that the color of these emulsion indicated possible coalescence changes (Figure 9). 


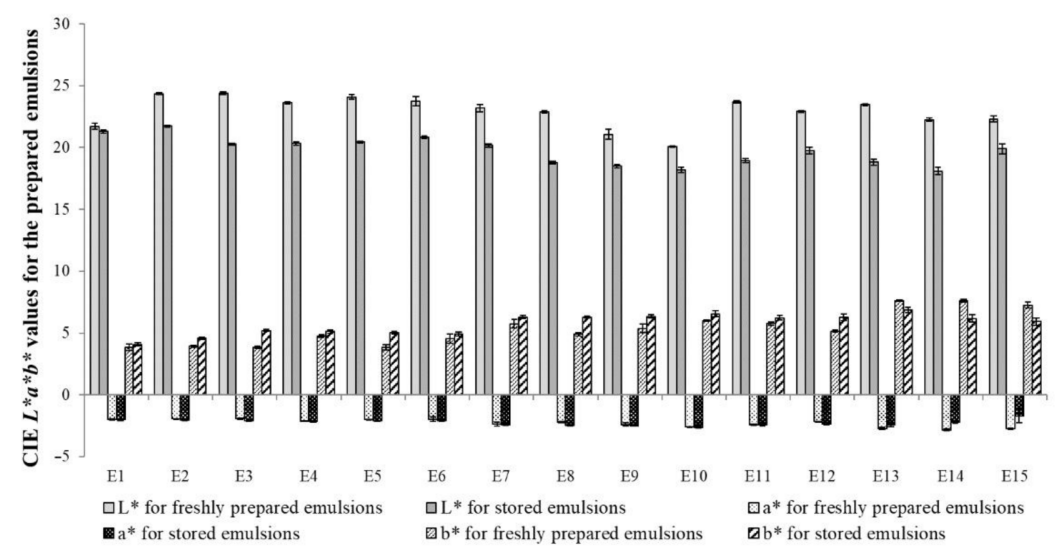

Figure 8. CIEL*a*b* values for the prepared emulsions measured $24 \mathrm{~h}$ after their preparation and 30 days of storage. Legend for E1-E15 is provided in Table 2.

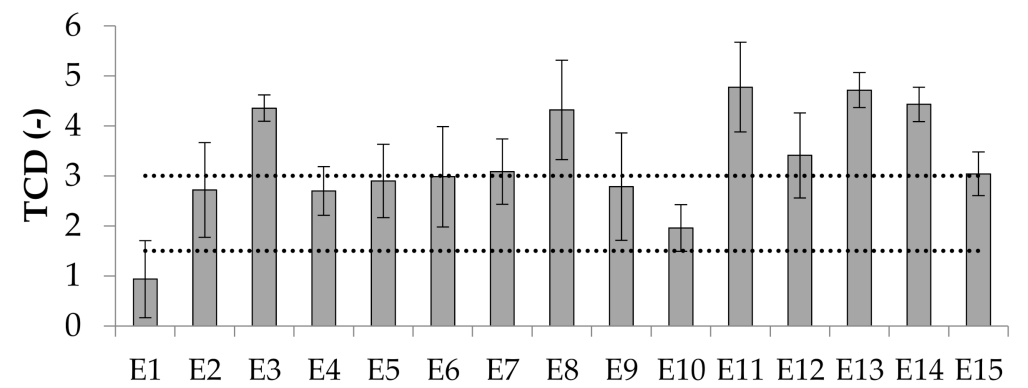

Figure 9. TCD values for emulsions E1-E15. Legend for E1-E15 is provided in Table 2.

The method most often used to determine the rheological properties of emulsion systems is the measurement of their viscosity. Emulsions consisting of a dispersed and continuous phases belong to the group of non-newtonian fluids, hence they can exhibit the characteristics of thinned or shear-thickened, plastic or viscoelastic fluids. The changes in emulsion viscosity that occur in emulsion systems during storage are therefore inevitable. Since changes in this parameter directly affect changes in the stability of these systems, it becomes justified to introduce stabilizing substances into the emulsion systems, while modifying their rheological properties. Taking into account the type of modified fat used as the fat phase of the emulsions, it was observed that the systems containing the highest share of mutton tallow in the fat blend (E1, E2, E3) were characterized by the highest viscosity (44.6-60.3 Pa*s). Comparable values were also recorded for three consecutive emulsions (E4-E6). Significantly low viscosity values (4.0-6.5 $\left.\mathrm{Pa}^{*} \mathrm{~s}\right)$ were recorded for the emulsions for which hemp seed oil was the predominant component in the fat phase. In all emulsions containing the same fat, the effect of the carboxymethylcellulose used was visible. The higher share of $\mathrm{CMC}$, the higher the viscosity value (Figure 10).

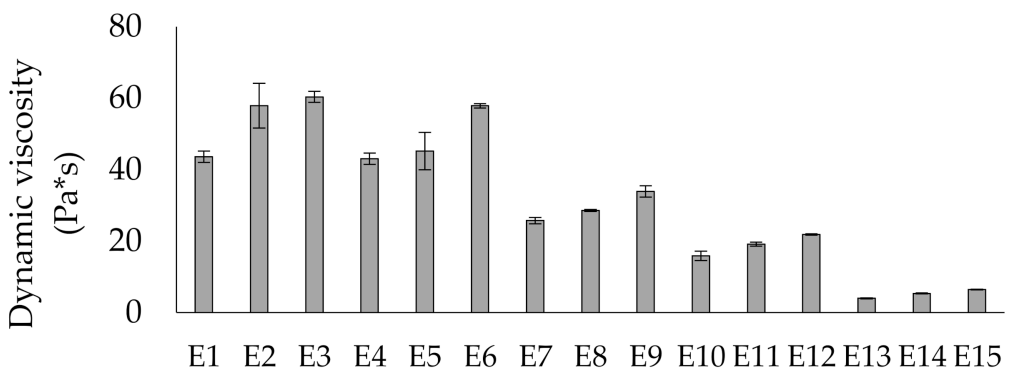

Figure 10. Dynamic viscosity of E1-E15 emulsions determined $24 \mathrm{~h}$ after their preparation. Legend for E1-E15 is provided in Table 2. 


\section{Materials and Methods}

\subsection{Materials}

Following materials were used: mutton tallow (MT) (Meat-Farm, Gmina Lesznowola, Poland), hemp seed oil (HSO) (Oleofarm, Wrocław, Poland), lipase from Rhizomucor miehei immobilized on immobead 150, $\geq 300 \mathrm{U} / \mathrm{g}$ (Sigma-Aldrich, Zwijndrecht, The Netherlands), carboxymethylcellulose (Barentz International BV, Hoofddorp, The Netherlands), preservative Euxyl K712 (Schülke \& Mayr GmbH, Norderstedt, Germany).

\subsection{Methods}

\subsubsection{Enzymatic Catalysis}

Before the reaction mutton tallow was bleached and deodorized, according to the method described in our previous study [25]. Reaction conditions were presented in Table 4. Reaction was performed in a shaker with water bath (SWB 22N, Labo Play, Bytom, Poland) and was stopped by filtering the enzyme.

Table 4. Interesterification reaction conditions.

\begin{tabular}{cc}
\hline Parameter & Details \\
\hline $\begin{array}{c}\text { MT:HSO ratios } \\
\text { Termostating of fat blends before the reaction } \\
\text { Catalyst type }\end{array}$ & $\begin{array}{r}75: 25,60: 40,50: 50,40: 60 \text { and } 25: 75(w / w) \\
60{ }^{\circ} \mathrm{C}, 15 \mathrm{~min}\end{array}$ \\
Catalyst amount & $\begin{array}{c}\text { lipase from } \text { Rhizomucor miehei immobilized on } \\
\text { immobead } 150, \geq 300 \mathrm{U} / \mathrm{g}\end{array}$ \\
Water amount & $5.0 \% \mathrm{w} / \mathrm{w}$ in relation to the fat blend mass \\
Reaction temperature & $1.1 \% \mathrm{w} / \mathrm{w}$ in relation to the fat blend mass \\
Reaction time & $60{ }^{\circ} \mathrm{C}$ \\
Shaking speed & $6 \mathrm{~h}$ \\
\end{tabular}

\subsubsection{Polar and Non-Polar Fractions Content}

Polar and non-polar fractions content was analyzed by means of gel permeation chromatography using Agilent 1100 series GPC system. Analysis conditions were detailed in our previous study [25].

\subsubsection{Antioxidant Activity}

Antioxidant activity was determined using radical scavenging activity-2,2-diphenyl1-picrylhydrazyl (DPPH) method according Sanchéz-Moreno et al. [26] method with modification. $0.4 \mathrm{~mL}$ of a sample was mixed with $3.6 \mathrm{~mL}$ of DPPH solution $(0.025 \mathrm{~g}$ DPPH in $100 \mathrm{~mL}$ ethanol). Then, the prepared solution was mixed for $20 \mathrm{~s}$ using vortex shaker (IKA shaker, Genius 3, Bayern Germany). The reaction was performed in darkness at $25{ }^{\circ} \mathrm{C}$. After $10 \mathrm{~min}$, the absorption was measured at a wavelength of $515 \mathrm{~nm}$ against ethanol using spectrophotometer Jenway (6405 UV/Vis, Stone, UK). As a standard Trolox (6-hydroxy-2,5,7,8-tetramethylchroman-2-carboxylic acid) (10-1000 mg/L; R2 = 0.998) was used. The obtained results were presented as $\mathrm{mM}$ Trolox equivalent antioxidant capacity (TEAC) $/ \mathrm{kg}$. All chemicals were analytical grade and were purchased from Reachem (Bratislava V, Slovakia) and Sigma Aldrich (Sant Louis, MO, USA).

\subsubsection{Oxidative Stability}

The oxidative stability of fats was determined by means of 892 Rancimat (Metrohm, Herisau, Switzerland). The determination was performed according to ISO standard 6886:1997 [27]. $2 \pm 0.01 \mathrm{~g}$ of a sample was used, the determination was performed at $120{ }^{\circ} \mathrm{C}$, under a constant air flow $(20 \mathrm{l} / \mathrm{h})$. All analyses were performed in triplicate.

\subsubsection{Texture}

Texture of fats were assessed using a Texture Analyzer CT3 (Brookfield Engineering Laboratories, Inc., Middleboro, MA, USA). The following measurement parameters were 
used: cone-shaped acrylic probe $\left(45^{\circ}\right)$, penetration depth $10 \mathrm{~mm}$, speed $0.1 \mathrm{~mm} / \mathrm{s}$, temperature: $20^{\circ} \mathrm{C}$. $24 \mathrm{~h}$ before the measurement, the samples were completely melted. Hardness and adhesive force were measured, and were defined as maximum and minimum of the peak (g), respectively. Measurements were performed in triplicate.

\subsubsection{Emulsion Preparation}

The composition of the prepared emulsions is shown in Table 4. The oil phase of the emulsions consisted of modified fats containing blends of mutton tallow and hemp seed oil in different ratios. The aqueous phase consisted of aqueous thickener solutions at different concentrations, prepared by dispersing CMC by means of magnetic stirrer (IKA, RCT Basic, Staufen, Germany) for $30 \mathrm{~min}$ and then homogenized for $1 \mathrm{~min}$ at 18,500 rmp using a ULTRA-TURRAX, model T18 equipped with S18G-19G dispersing head (IKA, Shanghai, China) and left for $24 \mathrm{~h}$ at room temperature. The oil and water phases were heated to $50-55{ }^{\circ} \mathrm{C}$ and then homogenized for $4 \mathrm{~min}$ at $18,500 \mathrm{rmp}$ using the homogenizer mentioned above. Then preservative was added after bringing them to room temperature.

\subsubsection{Turbiscan Analysis}

The emulsions destabilization was evaluated using Turbiscan Lab (Formulation, Toulouze, France). The determination principle and parameters were described in our previous study [25]. The data was presented as: TSI (Turbiscan stability index), mean $\triangle \mathrm{BS}(\%)$ in a middle zone of a measuring cell and peak thickness in a bottom zone of a measuring cell.

\subsubsection{Microscopic Analysis}

Microscopic analysis, including emulsions structure and mean droplet diameter, was performed using an optical microscope (Genetic Pro Trino, Delta Optical, Warszawa, Poland) equipped with a digital camera (DLT Cam Pro, Delta Optical, Gdansk, Poland) at a magnification of $400 \times$.

\subsubsection{Color of Emulsions}

Color evaluation was performed using a Konica Minolta chromameter CR-400 (Konica Minolta Sensing Inc., Milton Keynes, UK). Before the measurements chromameter was standardized with a white calibration plate. CIEL ${ }^{*}{ }^{*} b^{*}$ system was used. Total color difference was calculated according to the formula presented by Patras et al. [24]. Measurements were performed in triplicate.

\subsubsection{Viscosity of Emulsions}

The dynamic viscosity of the emulsions was determined using a Brookfield DV-III Ultra rheometer, model HA with a helipath spindle set (Brookfield Engineering Laboratories, Commerce Blvd, Middleboro, MA, USA). Spindle no. 92 (T-B) was used, and the determination was performed at $20^{\circ} \mathrm{C}$ at spindle speed of $10 \mathrm{rpm}$. Measurements were performed in triplicate.

\section{Conclusions}

The presented work showed that it is possible to obtain dispersion systems based on fats obtained as a result of enzymatic modification catalyzed by a selective lipase from Rhizomucor miehei. The study clearly showed that the more favorable dispersion systems were prepared on the basis of modified fats containing a greater proportion of mutton tallow. The presented emulsions are a model dispersion system that requires elaboration by introducing appropriate ingredients that increase the functionality of such a product. The addition of auxiliary substances into the system and the creation of the target product is dictated by the possible purpose of such an emulsion. According to the authors, such systems can be used in the chemical, food and cosmetic industries. 
Author Contributions: Conceptualization. M.K. and M.W.; methodology. M.W. and M.K.; validation. M.K. and M.W.; formal analysis. A.Z.; investigation. M.W., E.I. and A.M.; writing-original draft preparation. M.W.; writing_review and editing. M.K.; supervision. A.Z. All authors have read and agreed to the published version of the manuscript.

Funding: This research received no external funding.

Data Availability Statement: The data presented in this study are available on request from the corresponding author.

Acknowledgments: The authors would like to acknowledge the Kazimierz Pulaski University of Technology and Humanities in Radom, Warsaw University of Life Sciences and Slovak University of Agriculture for financial support.

Conflicts of Interest: The authors declare no conflict of interest.

\section{References}

1. De Araújo, M.E.M.B.; Campos, P.R.B.; Alberto, T.G.; Contesini, F.J.; de Oliveira Carvalho, P. Synthesis of structured triacylglycerols enriched in n-3 fatty acids by immobilized microbial lipase. Braz. J. Microbiol. 2016, 47, 1006-1013. [CrossRef] [PubMed]

2. Kowalska, M.; Woźniak, M.; Krzton-Maziopa, A.; Tavernier, S.; Pazdur, Ł.; Żbikowska, A. Development of the emulsions containing modified fats formed via enzymatic interesterification catalyzed by specific lipase with various amount of water. $J$. Dispers. Sci. Technol. 2019, 40, 192-205. [CrossRef]

3. Kowalska, M.; Zbikowska, A.; Tarnowska, K. Stability of emulsions containing interesterified fats based on mutton tallow and walnut oil. J. Am. Oil Chem. Soc. 2015, 92, 993-1002. [CrossRef]

4. Kim, B.H.; Akoh, C.C. Recent research trends on the enzymatic synthesis of structured lipids. J. Food Sci. 2015, 80, C1713-C1724. [CrossRef] [PubMed]

5. Speranza, P.; Leão, K.M.M.; Gomes, T.S.; Reis, L.V.C.; Rodrigues, A.P.; Macedo, J.A.; Ribeiro, A.P.B.; Macedo, G.A. Improving the chemical properties of Buriti oil (Mauritia flexuosa L.) by enzymatic interesterification. Grasas Aceites 2018, 69, e282. [CrossRef]

6. Ribeiro, A.P.B.; Basso, R.C.; Grimaldi, R.; Gioielli, L.A.; dos Santos, A.O.; Cardoso, L.P.; Gonçalves, L.A.G. Influence of chemical interesterification on thermal behavior. microstructure. polymorphism and crystallization properties of canola oil and fully hydrogenated cottonseed oil blends. Food Res. Int. 2009, 42, 1153-1162. [CrossRef]

7. Zaks, A.; Klibanov, A.M. The effect of water on enzyme action in organic media. J. Biol. Chem. 1988, 263, 8017-8021. [CrossRef]

8. Feltes, M.M.C.; de Oliveira, D.; Block, J.M.; Ninow, J.L. The production, benefits, and applications of monoacylglycerols and diacylglycerols of nutritional interest. Food Bioproc. Technol. 2013, 6, 17-35. [CrossRef]

9. Yamashita, Y.; Miyahara, R.; Sakamoto, K. Emulsion and emulsification technology. In Cosmetic Science and Technology-Theoretical Principles and Applications; Sakamoto, K., Lochhead, R.Y., Maibach, H.I., Yamashita, Y., Eds.; Elsevier: Amsterdam, The Netherlands, 2017; pp. 489-506.

10. McClements, D.J. Food Emulsions: Principles, Practices, and Techniques, 2nd ed.; CRC Press: Boca Raton, FL, USA, 1999.

11. McClements, D.J. Critical review of techniques and methodologies for characterization of emulsion stability. Crit. Rev. Food Sci. Nutr. 2007, 47, 611-649. [CrossRef]

12. Arancibia, C.; Navarro-Lisboa, R.; Zúñiga, R.N.; Matiacevich, S. Application of CMC as thickener on nanoemulsions based on olive oil: Physical properties and stability. Int. J. Polym. Sci. 2016, 2016, 6280581. [CrossRef]

13. Arancibia, C.; Bayarri, S.; Costell, E. Comparing carboxymethyl cellulose and starch as thickeners in oil/water emulsions. Implications on rheological and structural properties. Food Biophys. 2013, 8, 122-136. [CrossRef]

14. Oomah, B.D.; Busson, M.; Godfrey, D.V.; Drover, J.C. Characteristics of hemp (Cannabis sativa L.) seed oil. Food Chem. 2002, 76, 33-43. [CrossRef]

15. Kowalski, B.; Tarnowska, K.; Gruczynska, E.; Bekas, W. Chemical and enzymatic interesterification of a beef tallow and rapeseed oil equal-weight blend. Eur. J. Lipid Sci. Technol. 2004, 106, 655-664. [CrossRef]

16. Macrae, A.R. Lipase-catalyzed interesterification of oils and fats. J. Am. Oil Chem. Soc. 1983, 60, 291-294. [CrossRef]

17. Shahidi, F.; Zhong., Y. Novel antioxidants in food quality preservation and health promotion. Eur. J. Lipid Sci. Technol. 2010, 112, 930-940. [CrossRef]

18. Leonard, W.; Zhang., P.; Ying., D.; Fang., Z. Hempseed in food industry: Nutritional value, health benefits and industrial applications. Compr. Rev. Food Sci. Food Saf. 2020, 19, 282-308. [CrossRef]

19. Wirkowska-Wojdyła, M.; Bryś, J.; Górska, A.; Ostrowska-Ligęza, E. Effect of enzymatic interesterification on physiochemical and thermal properties of fat used in cookies. LWT 2016, 74, 99-105. [CrossRef]

20. Raikos, V.; McDonagh, A.; Ranawana, V.; Duthie, G. Processed beetroot (Beta vulgaris L.) as a natural antioxidant in mayonnaise: Effects on physical stability, texture and sensory attributes. Food Sci. Hum. Wellness 2016, 5, 191-198. [CrossRef]

21. Ledóchowska, E.; Datta, I. Wpływ frakcji nietriacyloglicerolowej na stabilność oksydatywną tłuszczu przeestryfikowanego chemicznie i enzymatycznie. Żywność Nauka Technol. Jakość 1999, 18, 15-23. (In Polish)

22. Kowalski, B.; Tarnowska, K.; Gruczyńska, E.; Bekas, W. Chemical and enzymatic interesterification of beef tallow and rapeseed oil blend with low content of tallow. J. Oleo Sci. 2004, 53, 479-488. [CrossRef] 
23. McClements, D.J. Food Emulsions: Principles, Practices, and Techniques, 3rd ed.; CRC Press: Boca Raton, FL, USA, 2015.

24. Patras, A.; Brunton, N.P.; Tiwari, B.K.; Butler, F. Stability and degradation kinetics of bioactive compounds and colour in strawberry jam during storage. Food Bioprocess Technol. 2011, 4, 1245-1252. [CrossRef]

25. Kowalska, M.; Woźniak, M.; Zbikowska, A.; Kozłowska, M. Physicochemical Characterization and Evaluation of Emulsions Containing Chemically Modified Fats and Different Hydrocolloids. Biomolecules 2020, 10, 115. [CrossRef] [PubMed]

26. Sánchés-Moreno, C.; Larrauri, A.; Saura-Calixto, F. A procedure to measure the antioxidant efficiency of polyphenols. J. Sci. Food Agric. 1998, 76, 270-276. [CrossRef]

27. International Organization for Standardization (ISO). ISO 6886:1997. Animal and Vegetable Fats and Oils-Determination of Oxidation Stability (Accelerated Oxidation Test); ISO: Geneva, Switzerland, 1997. 